\title{
Anti-Ascaris IgE as a Risk Factor for Asthma Symptoms among 5-Year-Old Children in Rural Bangladesh with Even Decreased Ascaris Infection Prevalence
}

\author{
Haruko Takeuchi $^{a}$ Sayaka Takanashi ${ }^{b}$ S.M. Tafsir Hasan ${ }^{c}$ Samar Kumar Hore ${ }^{d}$ \\ Sultana Yeasmin ${ }^{c}$ Shaikh Meshbahuddin Ahmad ${ }^{\mathrm{e}}$ Md Jahangir Alam ${ }^{\mathrm{e}}$ \\ Masamine Jimba ${ }^{a}$ Md Alfazal Khanc Tsutomu Iwata ${ }^{f}$ \\ aDepartment of Community and Global Health, Graduate School of Medicine, The University of Tokyo, \\ Tokyo, Japan; 'Department of Developmental Medical Sciences, Graduate School of Medicine, The University of \\ Tokyo, Tokyo, Japan; ' Nutrition and Clinical Services Division, icddr,b (International Centre for Diarrhoeal Disease \\ Research, Bangladesh), Dhaka, Bangladesh; ${ }^{\mathrm{d} C e n t r e ~ f o r ~ E q u i t y ~ a n d ~ H e a l t h ~ S y s t e m, ~ i c d d r, b, ~ D h a k a, ~ B a n g l a d e s h ; ~}$ \\ eInfectious Diseases Division, icddr,b, Dhaka, Bangladesh; fDepartment of Education for Childcare, Faculty of \\ Child Studies, Tokyo Kasei University, Sayama, Japan
}

\section{Keywords}

Anti-Ascaris lgE · Ascaris infection prevalence · Asthma symptoms · Bangladesh · Children

\footnotetext{
Abstract

Background: Epidemiological studies have indicated that anti-Ascaris IgE enhances asthma and allergies under specific conditions although the association between them is still controversial. The association of anti-Ascaris IgE with increased asthma symptoms among children from a general population with a mild to moderate Ascaris infection prevalence was investigated. Methods: A total of 126 children aged 5 years with wheezing during the previous year and 110 children who did not have wheezing were selected randomly from the rural service area of the International Centre for Diarrhoeal Disease Research, Bangladesh. Serum levels of total, anti-Ascaris, anti-Dermatophagoides pteronyssinus, and anti-cockroach lgEs were tested, and their risks for
}

wheezing were analyzed. The wheezing children were then classified by hierarchical cluster analysis to investigate the contribution of anti-Ascaris lgE to wheezing. Results: The anti-Ascaris IgE levels in wheezing and never-wheezing children were 1.07 and $0.65 \mathrm{U}_{\mathrm{A}} / \mathrm{mL}$, and it contributed to $11 \%$ of wheezing in children. Anti-Ascaris IgE was significantly associated with wheezing (odds ratio [OR] per $\log _{\mathrm{e}}$ increment: 1.37 [95\% Cl: 1.01-1.87], $p=0.046$ ). The ORs, which were adjusted for sex, parental asthma, pneumonia history, helminth infections, Haemophilus influenzae type B combination vaccination, antibiotic use during infancy, and total and specific IgE levels, increased even when only children with more specific symptoms of asthma were included in the analysis. Namely, the ORs for wheezing with sleep disturbance, four or more attacks, and wheezing with speech

Haruko Takeuchi and Sayaka Takanashi contributed equally, and Md Alfazal Khan and Tsutomu Iwata contributed equally.

Edited by: H.-U. Simon, Bern.
C 2022 The Author(s).

Published by S. Karger AG, Basel

This is an Open Access article licensed under the Creative Common Attribution-NonCommercial-4.0 International License (CC BY-NC) (http://www.karger.com/Services/OpenAccessLicense), applicable to the online version of the article only. Usage and distribution for commercial purposes requires written permission.
Correspondence to:

Haruko Takeuchi, htakeuchi-tky@umin.net 
difficulties during the previous 1 year were $O R=1.44 / \log _{\mathrm{e}}$ increment [95\% Cl: 1.01-2.07], OR $=1.90 / \log _{\mathrm{e}}$ increment [95\% Cl: 1.11-3.25], and OR $=1.78 / \log _{\mathrm{e}}$ increment $[95 \% \mathrm{Cl}$ : 1.01-3.14], respectively. Conclusions: The anti-Ascaris IgE levels in wheezing and never-wheezing children in the current study significantly decreased concurrently with Ascaris infection prevalence compared with their corresponding values in 2001. The contribution of anti-Ascaris IgE to wheezing also dropped from $26 \%$ in 2001 to $11 \%$ in the current study. Despite significant decreases in the levels and the seroprevalence and its contribution to wheezing, anti-Ascaris IgE remained significantly associated with increased risk of wheezing. Anti-Ascaris IgE significantly increased the risk of wheezing in a general population with a mild to moderate Ascaris infection prevalence, suggesting robustness as a risk factor and a possible dose-response relationship.

(C) 2022 The Author(s)

Published by S. Karger AG, Basel

\section{Introduction}

The main precipitating factors for asthma during childhood are atopy and lower respiratory tract infections [1]. Some helminth infections, especially Ascaris species, have also been reported to be associated with an increased risk of wheezing [2-4]. However, the relationship between helminth infection and asthma is controversial. Helminthic infections increased wheezing [2-7], suppressed wheezing $[6,8-10]$, or no effects are found [11]. Generally, the association between helminths and asthma appears to be more suppressive [6,8-10].

The prevalence of asthma has increased rapidly in high-income countries since the 1970s with a higher incidence among children living in urban and industrial areas than in those living in rural areas [12-16]. These findings brought about the hypothesis that helminthic infections protect against asthma and allergies by suppressing the host immune response. Some studies have shown that atopy is suppressed by the presence of chronic helminthic infection [17] and that helminths suppress wheezing [6, 8-10]. Among the various helminths, the suppressive function has been reported most in relation to schistosomiasis. Schistosoma and filaria seem to be associated with a milder course of asthma $[8,17]$ by enhancing IL-10 production and activating regulatory $\mathrm{T}$ cells $[17,18]$.

However, the suppressive association has rarely been documented in the context of ascariasis. A systematic review and meta-analysis of 22 studies revealed an association between Ascaris infection and wheezing [3]. Another systematic review of studies conducted in Latin America

Wheezing and Anti-Ascaris IgE with Decreased Ascaris Infection Prevalence also revealed a higher risk of asthma and wheezing in patients with Ascaris infections [4]. In studies conducted in China and South Africa, Ascaris infection was found to increase the risk of airway hyperreactivity (AHR), which is a hallmark clinical symptom of asthma $[2,19]$. It was also assumed that mild to moderate Ascaris infection accelerated allergic responses to environmental aeroallergens, while moderate to severe infections were protective against asthma.

However, epidemiological studies conducted among 5-year-old rural Bangladeshi children in 2001 and 2016 found neither a protective nor an enhancing association between wheezing and Ascaris infection [20, 21]. Remarkably, these studies found that wheezing prevalence decreased significantly from $16.1 \%$ in 2001 to $8.7 \%$ in 2016, despite a significant decrease in the prevalence of Ascaris infection from $76 \%$ in 2001 to $18 \%$ in 2016 . Nevertheless, those studies found that Ascaris infection neither protected against wheezing nor increased the risk of wheezing.

In 2001, anti-Ascaris immunoglobulin $\mathrm{E}$ (IgE) was found to increase the risk of childhood wheezing in a rural area of Bangladesh, where the prevalence of Ascaris infection was more than 75\% [20]. Furthermore, in 2005, anti-Ascaris IgE was found to increase the risk of childhood AHR in the same rural area [22]. Thus, anti-Ascaris IgE, but not Ascaris infection itself, was a risk factor for wheezing in an area where Ascaris infection prevalence was high. This is despite the general assumption that mild to moderate Ascaris infection increased allergic responses to environmental aeroallergens and that moderate to severe infections were protective against asthma [8].

In a study conducted in 2001, wheezing participants were classified into three distinct categories, and $26 \%$ of wheezing was associated with anti-Ascaris IgE [23]. Sixteen percent was due to a history of pneumonia during young childhood, and the other $58 \%$ might have been attributable to innate immunity to Ascaris infection [23]. These findings further demonstrate that anti-Ascaris IgE increases the risk of wheezing. The anti-parasitic effect of IgE antibodies against helminths is thought to be a normal component of host protection during infection [2428 ], and these antibodies do not usually play a role in allergic symptoms. However, allergic manifestations have been demonstrated in ascariasis and anisakiasis [26].

These results were later supported by another study showing that anti-Ascaris IgE increased the risk of current wheezing in an atopic population with a mild to moderate Ascaris infection prevalence [29]. Furthermore, anti-Ascaris IgE also increased the risk of current 
Fig. 1. Flowchart of the sampling procedure.

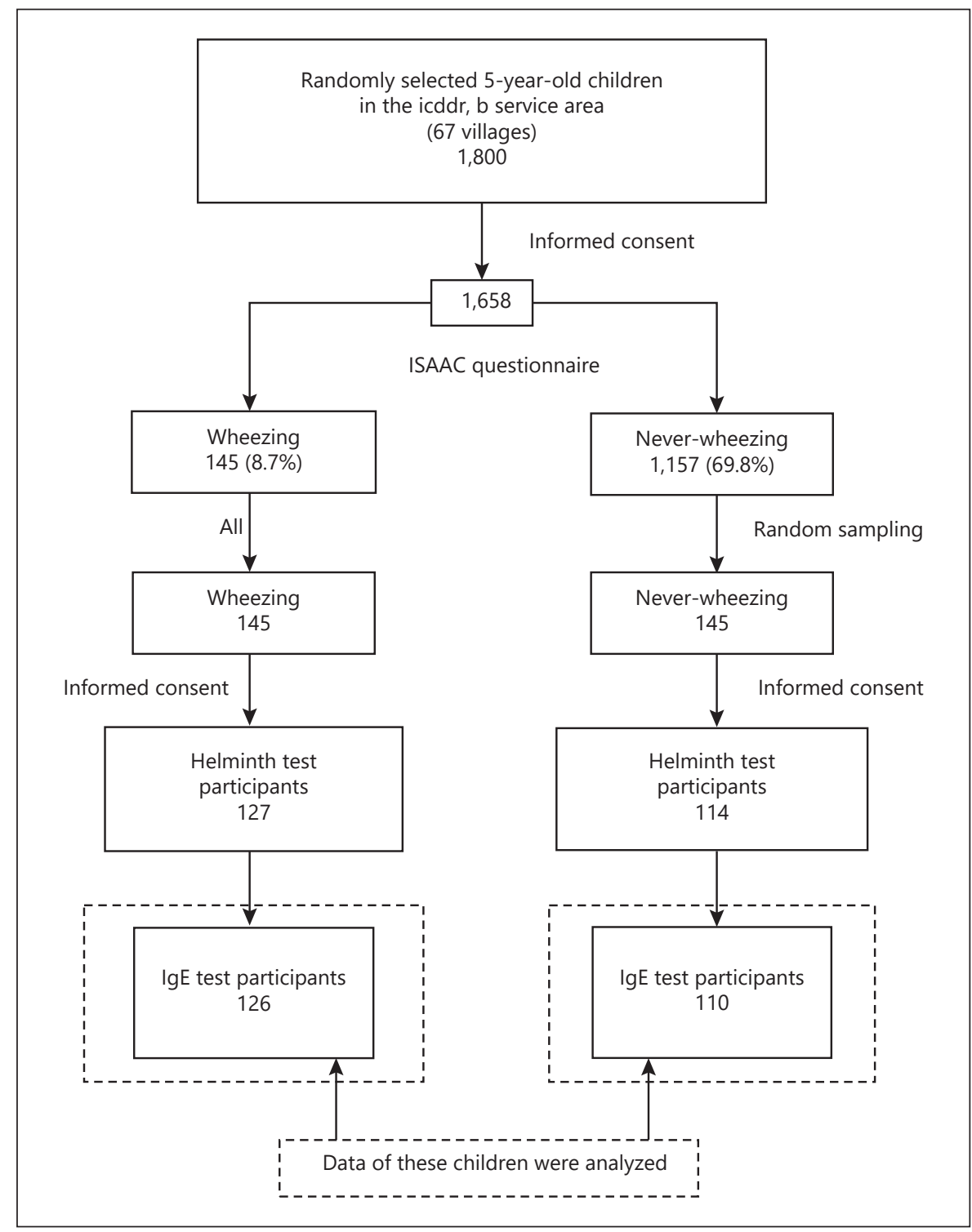

wheezing among children in a general population in an area with a moderate to high Ascaris infection prevalence [30]. In addition, anti-Ascaris IgE increased the risk of wheezing in a population whose mothers received additional caloric intake during pregnancy in an area with a mild to moderate Ascaris infection prevalence [31]. However, no study has investigated anti-Ascaris IgE as a risk factor for current wheezing in the general population of an area with a mild to moderate Ascaris infection prevalence.

Therefore, this study aimed to investigate whether anti-Ascaris IgE increases the risk of wheezing in a general population in an area with a mild to moderate Ascaris in- fection prevalence in rural Bangladesh. The study also analyzed the contribution of anti-Ascaris IgE to wheezing in children with wheezing.

\section{Methods}

Study Site and Participants

This study was conducted from December 2015 to October 2016 in Matlab in rural Bangladesh. The International Centre for Diarrhoeal Disease Research, Bangladesh (icddr,b), has been maintaining a health and demographic surveillance system that consists of regular cross-sectional censuses and the longitudinal registration of vital events since 1966 [32]. The details of the study site and the procedures used for data collection are described else- 
where [21]. In brief, 1,800 5-year-old children were randomly selected from all the 67 villages of the icddr,b service area and were asked to participate in the study. A total of 1,658 children responded to the questionnaire of the International Study of Asthma and Allergies in Childhood. We identified 145 (8.7\%) children with wheezing and 1,154 (69.8\%) children who had never experienced wheezing. For this case-control study, only children with wheezing and those who had never experienced wheezing were included. The remaining 356 children ever experienced wheezing and were excluded from the analysis. After identifying the children with wheezing, we randomly selected an equal number of children as controls who had never experienced wheezing. Then, the contributing factors to wheezing were analyzed on the wheezing children (shown in Fig. 1). Five-year-old children were chosen as the participants since the present study aimed to investigate the effect of anti-Ascaris IgE on childhood wheezing and tried to compare the result with our previous study conducted on 5-year-old children in the same area.

\section{Data Collection}

Field data were collected as described elsewhere [21]. In brief, written informed consent and information on wheezing, family history of allergy, and socioeconomic status were collected by trained local field research assistants. Wheezing was defined as any episode of wheezing or whistling in the chest 1 year before the interview. Children who had never experienced an episode of wheezing or whistling in the chest were grouped as never-wheezing children. Information on the participants' history of pneumonia was collected from the Matlab Hospital database. Children brought 50 $\mathrm{g}$ of stool samples from home, and $7 \mathrm{~mL}$ of venous blood was collected from each child at the hospital.

Fresh stool specimens were analyzed as described elsewhere [21]. The FEIA method (Pharmacia KK, Tokyo, Japan) was employed to measure serum IgE levels. The CAP-FEIA System (Pharmacia KK) was used to measure anti-Dermatophagoides pteronyssinus (Der p), anti-cockroach, and anti-Ascaris lumbricoides IgEs.

\section{Statistical Analysis}

Data were analyzed using IBM SPSS Statistics, version 26 (IBM Japan, Tokyo, Japan). The sample size was calculated by assuming that wheezing would be experienced by at least $16 \%$ of children aged 60-71 months [20]. We calculated that 209 children in each group would provide $80 \%$ power to detect a difference in the log serum levels of anti-Ascaris $\operatorname{IgE}$ of $1.8 \mathrm{U}_{\mathrm{A}} / \mathrm{mL}$ (SD 1.5) and $1.4 \mathrm{U}_{\mathrm{A}} /$ $\mathrm{mL}$ (SD 1.4) with a two-sided type 1 error of $5 \%$. To achieve this, we had to approach 240 wheezing and 240 never-wheezing children, assuming a $15 \%$ rate of refusal or absences. We approached 1,800 individuals with a $20 \%$ loss to obtain the required number of wheezing children.

This study was a nested case-control study, and the independent variables were between subjects. First, we compared the prevalence of wheezing and other asthma symptoms reported in 2001 and 2016. After the following descriptive analysis of the wheezing and never-wheezing participants, continuous variables, such as height, total IgE, anti-Ascaris IgE, anti-Der $p$ IgE, and anti-cockroach $\operatorname{IgE}$, were compared using a $t$ test, and categorical variables were compared using a $\chi^{2}$ test. The significance level for all statistical analyses was set at $p<0.05$.

Then, we calculated and compared the geometric mean levels of total and specific IgE levels and in the children also with more specific symptoms of asthma. Then, we calculated the odds ratios (ORs) for wheezing of the independent variables by logistic regression analysis with the wheezing status as the outcome variable. Subsequently, the ORs of total and specific IgE levels were recalculated after excluding children with less specific symptoms of asthma.

Finally, cluster analysis was performed using Ward's hierarchical clustering method. The variables were standardized to equalize the standard deviations of the variables' scales. To compare differences among the clusters, analysis of variance without the following analysis was used for continuous variables, and the $\chi^{2}$ test was used for categorical variables.

Of the independent variables between the wheezing and neverwheezing participants in the first descriptive analyses, height and weight, total IgE, anti-Ascaris IgE, anti-Der $p$ IgE, anti-cockroach $\mathrm{IgE}$, and monthly household income were continuous variables, and sex, helminths infections, history of pneumonia, parental asthma, history of vaccination, and antibiotic use during infancy were categorical variables. The distribution of the independent variables in each dependent group was checked to see the normality of the data. The analysis of linearity of the data was not necessary, since the dependent variable was a dichotomous variable. The correlation coefficient of the independent continuous variables was checked to see the collinearity. The IgE data were log transformed since they were skewed to the right or bimodal. The out layers were not excluded from the analysis, and the samples with missing data were excluded from the analysis.

The continuous variables between the two groups were compared using a two-tailed $t$ test, and categorical variables were compared using a both-sided $\chi^{2}$ test or Fisher exact test. The forced entry method was used in the logistic regression models to calculate the ORs for the risk factors. The included covariates were selected when the difference between the two outcome groups was significant $(p<0.05)$ in the first descriptive analyses or known as risk factors for wheezing. The collinearity was assessed by calculating the variance inflation factor.

\section{Results}

\section{Anti-Ascaris IgE as a Risk Factor for Wheezing}

Blood and stool samples were obtained from 127 (88\%) and 114 (79\%) wheezing and never-wheezing children, respectively. Whole data were available for 126 wheezing and 110 never-wheezing children, who constituted the study population. The datasets used for the analyses are in the online supplementary Datasets 1-5 (see www.karger.com/doi/10.1159/000521717 for all online suppl. material).

Anti-Ascaris IgE significantly increased the risk of wheezing (crude OR $=1.24 / \log _{\mathrm{e}}$ increment $[95 \% \mathrm{CI}$ : 1.04-1.47]) (Table 1). The OR for wheezing in relation to anti-Ascaris IgE increased when only the children showing more specific symptoms of asthma, such as sleep disturbance, four or more attacks, and speech difficulties during the previous 1 year, were included as wheezers 
Table 1. Odds ratios for current wheezing relative to the total, anti-Ascaris, and anti-DP IgE including when children with less specific asthma symptoms were excluded

\begin{tabular}{|c|c|c|c|c|c|c|c|}
\hline & $\begin{array}{l}\text { Wheezers/ } \\
\text { nonwheezers }\end{array}$ & $\begin{array}{l}\text { Units of } \\
\text { change }\end{array}$ & $\begin{array}{l}\text { Crude odds ratio } \\
(95 \% \mathrm{Cl})\end{array}$ & $p$ value & $N$ & $\begin{array}{l}\text { Adjusted odds ratio } \\
(95 \% \mathrm{Cl})\end{array}$ & $p$ value \\
\hline \multicolumn{8}{|c|}{ Anti-Ascaris $\lg \mathrm{E}\left(\log _{\mathrm{e}}\right.$ transformed)\| } \\
\hline Sleep disturbance ${ }^{\dagger}$ & $85 / 110$ & 1 & $1.25(1.04-1.51)$ & 0.018 & 190 & $1.44(1.01-2.07)$ & 0.046 \\
\hline$\geq 4$ attacks $^{\ddagger}$ & $33 / 110$ & 1 & $1.36(1.30-1.80)$ & 0.030 & 141 & $1.90(1.11-3.25)$ & 0.019 \\
\hline Speech disturbance ${ }^{\S}$ & $29 / 110$ & 1 & $1.44(1.06-1.94)$ & 0.018 & 136 & $1.78(1.01-3.14)$ & 0.048 \\
\hline Current wheezing & $125 / 108$ & 1 & $1.13(0.90-1.42)$ & 0.311 & 231 & $0.86(0.57-1.29)$ & 0.467 \\
\hline Sleep disturbance ${ }^{\dagger}$ & $84 / 108$ & 1 & $1.14(0.89-1.47)$ & 0.301 & 190 & $0.87(0.54-1.39)$ & 0.554 \\
\hline$\geq 4$ attacks $^{\ddagger}$ & $33 / 108$ & 1 & $1.23(0.88-1.73)$ & 0.233 & 141 & $0.63(0.33-1.20)$ & 0.160 \\
\hline Speech disturbance ${ }^{\S}$ & $28 / 108$ & 1 & $1.39(0.95-2.04)$ & 0.094 & 136 & $0.85(0.39-1.84)$ & 0.681 \\
\hline \multicolumn{8}{|c|}{ Anti-DP IgE (loge transformed $)^{+\dagger}$} \\
\hline Current wheezing & $126 / 110$ & 1 & $1.03(0.88-1.20)$ & 0.747 & 231 & $0.93(0.69-1.24)$ & 0.611 \\
\hline Current wheezing & $125 / 108$ & 1 & $1.00(0.86-1.17)$ & 0.959 & 231 & $0.98(0.73-1.33)$ & 0.915 \\
\hline Sleep disturbance ${ }^{\dagger}$ & $84 / 108$ & 1 & $1.01(0.85-1.19)$ & 0.931 & 190 & $0.96(0.67-1.36)$ & 0.806 \\
\hline$\geq 4$ attacks $^{\ddagger}$ & $33 / 108$ & 1 & $1.11(0.89-1.38)$ & 0.362 & 141 & $1.09(0.68-1.73)$ & 0.723 \\
\hline Speech disturbance ${ }^{\S}$ & $28 / 110$ & 1 & $1.14(0.89-1.44)$ & 0.302 & 136 & $1.00(0.61-1.6)$ & 0.998 \\
\hline
\end{tabular}

IgE, immunoglobulin E; 95\% Cl, 95\% confidence interval; OR, odds ratio; Anti-DP, anti-Dermatophagoides pteronyssinus. ${ }^{\dagger}$ Individuals without sleep disturbance during the previous 1 year were excluded from the analysis. ${ }^{\ddagger}$ Individuals with $<4$ wheezing attacks during the previous 1 year were excluded from the analysis. ${ }^{\S}$ Individuals without speech disturbance caused by wheezing during the previous 1 year were excluded from the analysis. "OR was adjusted for sex, pneumonia, parental asthma, helminth infections, pentavalent vaccine, antibiotic use, total, anti-DP, and anti-cockroach IgE. " OR was adjusted for sex, pneumonia, parental asthma, helminth infections, pentavalent vaccine, antibiotic use, anti-Ascaris, anti-DP, and anti-cockroach IgE. ${ }^{+\dagger}$ OR was adjusted for sex, pneumonia, parental asthma, helminth infections, pentavalent vaccine, antibiotic use, total, anti-Ascaris, and anti-cockroach lgE. ${ }^{\ddagger \ddagger}$ OR was adjusted for sex, pneumonia, parental asthma, helminth infections, pentavalent vaccine, antibiotic use, total, anti-Ascaris, and anti-DP IgE.

with or without adjustment for covariates (Table 1). In contrast, the OR of total IgE, anti-Derp IgE, or anti-cockroach IgE did not show any significant association with wheezing.

Anti-Ascaris IgE levels in the wheezing and neverwheezing groups in the present study $(1.07$ and 0.65 $\mathrm{U}_{\mathrm{A}} / \mathrm{mL}$, respectively) dropped significantly $(p<0.001$ and $p<0.001$, respectively) compared with those in the corresponding groups in the 2001 study (16.92 and 7.92 $\mathrm{U}_{\mathrm{A}} / \mathrm{mL}$, respectively). Similarly, the seroprevalence of anti-Ascaris IgE in both groups in the present study (57.1\% and $43.6 \%$, respectively) was significantly lower than that in the corresponding groups in the 2001 study ( $97 \%$ and $85.7 \%$, respectively; $p=0.009$ ). In addition, the prevalence of Ascaris infection in the wheezing and never-wheezing groups, respectively, decreased from $75 \%$ and $72 \%$ in 2001 to $19 \%$ and $10 \%$ in the present study.
The characteristics of the study population are shown in Table 2. Eggs of A. lumbricoides and Trichuris trichiura were detected in $19 \%$ and $22 \%$, respectively, of the stool of wheezing children; however, there were no significant differences from the never-wheezing children. Eggs from other helminth species were not detected in the study population. Parental asthma and the use of antibiotics up to the age of 1 year had positive associations with wheezing. In contrast, administration of the Haemophilus influenzae type $\mathrm{B}$ (Hib) combination vaccine (Shan $5^{\mathrm{TM}}$; Shantha Biotechnics, Telangana, India) in the form of a pentavalent vaccine that included a diphtheria, tetanus, pertussis, hepatitis $B$, and Hib vaccine was found to be protective against wheezing [33]. These variables were used for subsequent adjustments in the logistic regression models described in the above paragraph. In this study, a history of pneumonia at the age of 2 years or above was not associated with increased wheezing. 
Table 2. Description of the characteristics of the population and the variables used for adjustment, stratified by presence of wheezing

\begin{tabular}{|c|c|c|c|c|c|}
\hline & & $\begin{array}{l}\text { Wheezers, } \\
n(\%)\end{array}$ & $\begin{array}{l}\text { Never-wheezers, } \\
n(\%)\end{array}$ & Crude odds ratio & $p$ value \\
\hline Male/female & & $63(50) / 63$ & $45(41) / 65$ & $1.44(0.86-2.42)$ & 0.163 \\
\hline Helminth infection & & 126 & 110 & & \\
\hline Ascaris & Yes & $24(19)$ & $11(10)$ & $2.12(0.99-4.55)$ & 0.055 \\
\hline Trichuris & Yes & $28(22)$ & $17(15)$ & $1.56(0.80-3.04)$ & 0.189 \\
\hline History of pneumonia, years at & & 126 & 110 & & \\
\hline 0 & Yes & $4(3)$ & $2(2)$ & $0.57(0.10-3.15)$ & 0.514 \\
\hline 1 & Yes & $7(6)$ & $1(1)$ & $6.41(0.78-52.96)$ & 0.085 \\
\hline 2 & Yes & $8(6)$ & $1(1)$ & $7.39(0.91-60.05)$ & 0.061 \\
\hline $3-4$ & Yes & $7(6)$ & $0(0)$ & - & 1.000 \\
\hline Asthmatic father & Yes/total & $16 / 126(13)$ & $5 / 110(5)$ & $3.08(1.09-8.72)$ & 0.034 \\
\hline Asthmatic mother & Yes/total & $22 / 126(18)$ & $5 / 110(5)$ & $4.49(1.64-12.30)$ & 0.004 \\
\hline Penta vaccination ${ }^{\dagger}$ & Yes/total & $107 / 126(85)$ & $106 / 110(96)$ & $0.21(0.070-0.65)$ & 0.006 \\
\hline Antibiotics in infancy ${ }^{\ddagger}$ & Yes/total & $121 / 126(97)$ & $98 / 110(89)$ & $3.70(1.16-11.85)$ & 0.027 \\
\hline Monthly household income $e^{\S}$ & BDTk\| & $12,887(11,362-14,618)$ & $113,467(11,920-15,230)$ & $0.91(0.62-1.32)$ & 0.909 \\
\hline
\end{tabular}

BDTk, Bangladeshi taka. ${ }^{\dagger}$ Hib combination vaccine, including diphtheria, tetanus and pertussis vaccine, hepatitis B vaccine, and Hib vaccine. ${ }^{\ddagger}$ Antibiotics were administered during infancy. ${ }^{\S}$ Monthly household income (median, interquartile range). ${ }^{1}$ BDTk $=$ USD 0.012.

Table 3. Geometric mean levels of total, anti-Ascaris, anti-DP, and anti-cockroach lgEs

\begin{tabular}{|c|c|c|c|c|c|}
\hline Current wheezer & 126 & $734(606-890)$ & $1.07(0.81-1.41)$ & 0.77 (0.58-1.03) & $1.64(1.23-2.20)$ \\
\hline Sleep disturbance & 85 & 752 (591-955) & $1.13(0.79-1.62)$ & $0.81(0.58-1.14)$ & $1.66(1.16-2.37)$ \\
\hline$\geq 4$ attacks & 33 & $834(561-1,240)$ & $1.24(0.79-1.94)$ & $1.04(0.57-1.88)$ & $2.25(1.19-4.25)$ \\
\hline
\end{tabular}

IgE, immunoglobulin E; SD, standard deviation; Anti-DP, anti-Dermatophagoides pteronyssinus.

The distribution of anti-Ascaris, anti-Der $p$, and anticockroach IgE levels showed two peaks corresponding to the seropositive and seronegative individuals, while the total IgE levels showed almost normal distribution in both the wheezing and never-wheezing groups. The wheezing children were significantly more seropositive $\left(\geq 0.7 \mathrm{U}_{\mathrm{A}} / \mathrm{mL}\right)$ for anti-Ascaris IgE than the never-wheezing children ( $72 / 54$ vs. $48 / 62 ; \chi^{2}$ test: $\left.p=0.038\right)$. However, this association was not found in relation to anti-Der $p$ or anti-cockroach IgEs (66/60 vs. 53/57, $\chi^{2}$ test: $p=0.520$; $89 / 36$ vs. $75 / 33, \chi^{2}$ test: $p=0.770$, respectively).

Table 3 indicates the geometric mean of total, antiAscaris, anti-Der $p$, and anti-cockroach IgE levels. The geometric mean anti-Ascaris IgE level was significantly higher in the wheezing group than in the never-wheezing group ( $t$ test: $p=0.014)$. However, the geometric mean total IgE level in the wheezing children was not significantly higher than that in the never-wheezing children $(t$ test: $p=0.554)$. No significant differences were observed in the anti-Der $p$ and anti-cockroach IgE levels between wheezing and nonwheezing children ( $t$ test: $p=0.748$ and 0.823 , respectively). The geometric mean anti-Ascaris $\operatorname{IgE}$ levels for wheezing children who had more specific symptoms of asthma (e.g., sleep disturbance, four or more attacks, and speech difficulty) in the preceding 12 months were higher than those for the children who were merely wheezing. However, the differences were not significant ( $t$ test: $p=0.575,0.382$, and 0.356 , respectively).

\section{Cluster Analysis}

Three clusters were identified in wheezing children using hierarchical cluster analysis. As shown in Figure 2, the 


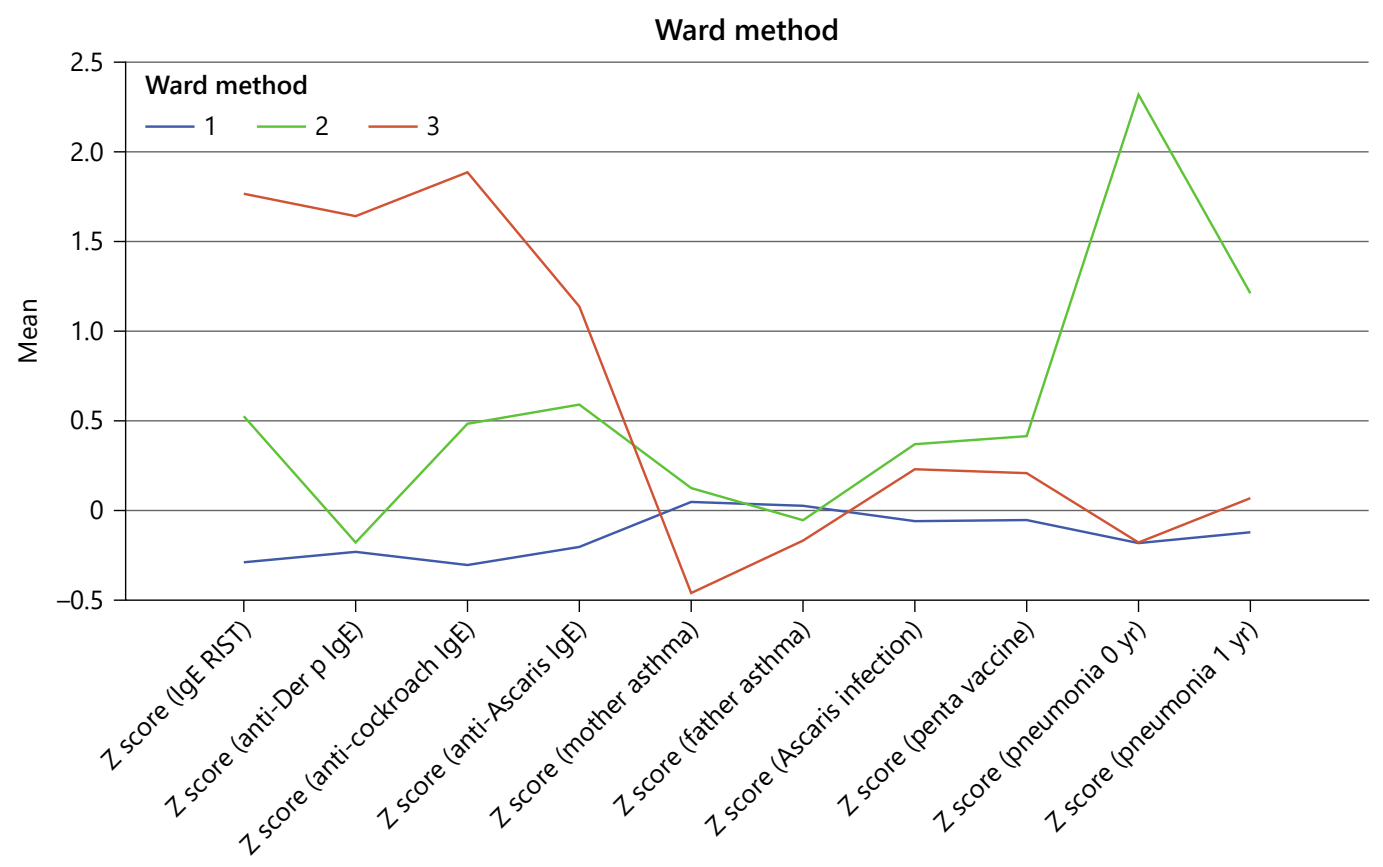

Fig. 2. The mean standardized value of the characteristic variables of the 3 clusters. Three clusters were identified. The vertical axis of this polygonal line graph expresses the mean standardized value of the variables regarding the characteristics of the clusters. The horizontal axis expresses each variable involved in the analysis: a history of pneumonia at zero and 1 year of age, pentavalent vaccina- tion, Ascaris infection intensity, parental asthma, and total and specific IgE levels. Cluster 1 expresses the group with low levels of pneumonia and low anti-Ascaris IgE titers, cluster 2 expresses the group with more frequent pneumonia and lower IgE levels, and cluster 3 expresses the group with the highest total, anti-Ascaris, anti-Der $p$, and anti-cockroach IgE titers and the least pneumonia. children in cluster 1 experienced low levels of pneumonia and had the lowest anti-Ascaris IgE titers. Cluster 2 experienced pneumonia most frequently and had lower $\operatorname{IgE}$ levels. Cluster 3 had the highest total, anti-Ascaris, anti$\operatorname{Der} p$, and anti-cockroach IgE titers and experienced pneumonia the least. The total and specific IgE levels, seroprevalence of specific IgEs, prevalence of Ascaris infection, and pneumonia history are shown in Table 4 . The physical status, family history, vaccination history, and socioeconomic characteristics of the three groups are shown in Table 5.

\section{Cluster 3}

Cluster 3 comprised $11 \%$ of the participants $(n=14)$. The significant characteristics of this cluster were higher total, anti-Ascaris, anti-Der $p$, and anti-cockroach IgE levels. Moreover, the history of pneumonia was lowest when they were aged $0,1,2$, and 3-4 years. The seroprevalence of anti-Ascaris IgE was significantly higher than that of cluster 1 , cluster 2 , and the never-wheezing chil- dren (Fisher two-tailed exact test: $p<0.001,<0.001$, and $<0.001$, respectively). Although the seroprevalence of anti-Ascaris IgE in wheezing children was $57 \%$, only $20 \%$ of them belonged to this cluster.

\section{Cluster 2}

Cluster 2 comprised the smallest cluster $(n=9 ; 7 \%)$. Children in this cluster experienced pneumonia most when they were $0,1,2$, and 3-4 years old. Their monthly household income was the lowest among the three groups, although the difference was not significant.

\section{Cluster 1}

Cluster 1 comprised the largest group ( $n=101 ; 81 \%$ ). It consisted of children who experienced pneumonia the least and had the lowest total, anti-Ascaris, anti-Der $p$, and anti-cockroach IgE serum levels. The levels were almost equal to those of the never-wheezing children. The seroprevalence of anti-Ascaris IgE was significantly lower than that of cluster 3 (Fisher two-tailed exact test: $p<$ 
Table 4. Comparisons of serum IgE levels, IgE seroprevalence, helminth infections, and pneumonia history among the three groups

\begin{tabular}{|c|c|c|c|c|}
\hline & Cluster 1 & Cluster 2 & Cluster 3 & $p$ value \\
\hline$n(\%$ per 114$)$ & $101(81)$ & $9(7)$ & $14(11)$ & \\
\hline Total lgE (mean $\pm S D), I U / m L$ & $553(460-666)$ & $1,802(1,150-2,824)$ & $3,421(2,360-4,958)$ & $<0.001$ \\
\hline Anti-Ascaris $\lg \mathrm{E}$ (mean $\pm \mathrm{SD}), \mathrm{U}_{\mathrm{A}} / \mathrm{mL}$ & $0.80(0.61-1.06)$ & $1.77(0.46-6.86)$ & $7.46(4.16-13.37)$ & $<0.001$ \\
\hline Anti-Der $p \lg \mathrm{E}(\operatorname{mean} \pm \mathrm{SD}), \mathrm{U}_{\mathrm{A}} / \mathrm{mL}$ & $0.57(0.42-0.76)$ & $1.14(0.50-2.62)$ & $6.29(2.91-13.58)$ & $<0.001$ \\
\hline $\begin{array}{l}\text { Anti-cockroach lgE (mean } \pm S D), U_{A} / m L \\
\text { Seropositive, } n(\%)\end{array}$ & $1.15(0.86-1.55)$ & $3.89(1.31-11.49)$ & $14.45(8.86-23.56)$ & $<0.001$ \\
\hline Anti-Ascaris lgE & $52(52)$ & $5(55)$ & $14(100)$ & 0.003 \\
\hline Anti-Der $p \lg \mathrm{E}$ & $47(47)$ & $5(56)$ & $13(93)$ & 0.005 \\
\hline Anti-cockroach lgE & $66(65)$ & $9(100)$ & $14(100)$ & 0.004 \\
\hline \multicolumn{5}{|l|}{ Helminth infection (+), $n(\%)$} \\
\hline Ascaris & $17(17)$ & $3(33)$ & $4(29)$ & 0.317 \\
\hline Trichuris & $21(21)$ & $4(44)$ & $2(14)$ & 0.199 \\
\hline \multicolumn{5}{|l|}{ Pneumonia history (+) } \\
\hline 0 years & $0(0)$ & $4(44)$ & $0(0)$ & $<0.001$ \\
\hline 1 year & $3(3)$ & $3(33)$ & $1(7)$ & 0.001 \\
\hline 2 years & $3(3)$ & $5(56)$ & $0(0)$ & $<0.001$ \\
\hline $3-4$ years & $0(0)$ & $6(67)$ & $0(0)$ & $<0.001$ \\
\hline
\end{tabular}

IgE, immunoglobulin E; Dp, Dermatophagoides pteronyssinus.

Table 5. Comparisons of physical status, family history, vaccination history, and sociodemographic characteristics of the three groups

\begin{tabular}{|c|c|c|c|c|}
\hline & Cluster 1 & Cluster 2 & Cluster 3 & $p$ value \\
\hline$N(\%)$ & $101(81)$ & $9(7)$ & $14(11)$ & \\
\hline Sex (female), $n(\%)$ & $51(51)$ & $2(22)$ & $8(57)$ & 0.219 \\
\hline \multicolumn{5}{|l|}{ Anthropometry } \\
\hline Height (mean \pm SD), $\mathrm{cm}$ & $107(106-108)$ & $105(101-110)$ & $107(106-108)$ & 0.637 \\
\hline Weight (mean \pm SD), kg & $16(16-17)$ & $15(13-17)$ & $16(15-17)$ & 0.249 \\
\hline \multicolumn{5}{|l|}{ Vaccine coverage, $n(\%)$} \\
\hline Hib combined & $84(83)$ & $9(100)$ & $13(93)$ & 0.276 \\
\hline \multicolumn{5}{|l|}{ Parental asthma, yes, $n$ (\%) } \\
\hline Mother & $20(20)$ & $2(22)$ & $0(0)$ & 0.179 \\
\hline Father & $14(14)$ & $1(11)$ & $1(7)$ & 0.745 \\
\hline \multicolumn{5}{|l|}{ Monthly income ${ }^{\dagger}$} \\
\hline BDTk $^{\ddagger}$ & $17,742(13,929-21,556)$ & $12,222(6,258-18,186)$ & $18,207(9,364-27,051)$ & 0.679 \\
\hline
\end{tabular}

BDTk, Bangladesh taka. ${ }^{\dagger}$ Monthly income (median interquartile range). ${ }^{\ddagger} 1$ BDTk $=$ USD 0.012 .

0.001 ), and there was no significant difference between the wheezing and never-wheezing children ( $\chi^{2}$ test: $p=$ 0.254 ). This group was the least likely to produce total and specific IgEs, and the prevalence of Ascaris infection (17\%) was the lowest, although the differences between the three groups were not significant.

\section{Discussion}

The present study found novel evidence that anti-Ascaris IgE significantly increased the risk of wheezing among children aged 5 years from the general population of an area with a mild to moderate Ascaris infection prevalence. This is partially consistent with the findings of several other studies that identified anti-Ascaris $\operatorname{IgE}$ as a 
risk factor for wheezing under some specific conditions. One study was conducted in the same region of Bangladesh in 2008, where Ascaris infection prevailed in approximately $17.4 \%$ of children. In that study, anti-Ascaris IgE increased the risk of ever having asthma among children aged 5 years whose mothers received additional caloric intake during pregnancy [31]. Similarly, a study conducted in northeastern Ecuador provided evidence that the risk of wheezing increased when anti-Ascaris IgE was present, independent of serum specific IgE levels in both atopic and nonatopic children from the general population [30]. Another study showed that anti-Ascaris IgE increased the risk of current wheezing in an atopic population with a mild to moderate Ascaris infection prevalence [29]. Combined with these findings, the results of the present study suggest that anti-Ascaris IgE increases the risk of wheezing irrespective of Ascaris infection prevalence. Anti-Ascaris IgE had also been presented to significantly increase the risk of AHR in 5-year-old wheezing children in a high endemic area [21].

Besides, despite the significant drops in the anti-Ascaris IgE levels, seroprevalence, and Ascaris infection prevalence, the anti-Ascaris IgE levels were significantly higher in the wheezing children than nonwheezing children in the current study and still increased the risk of wheezing $[19,20]$. Namely, anti-Ascaris IgE was proven to robustly increase the risk of wheezing, irrespective of the prevalence of Ascaris infection. Contrary to these facts, no significant difference was found in the infection prevalence when stratified by wheezing type in either the 2001 or 2016 study. The prevalence of Ascaris infection decreased due to the national deworming program implemented during that period [20].

The OR for wheezing in relation to anti-Ascaris $\operatorname{IgE}$ was enhanced when only children with more specific symptoms of asthma were included in the analysis. This may indicate that anti-Ascaris IgE and wheezing increased in a dose-dependent manner, suggesting a causal relationship. Anti-helminth IgE has been reported to cause Th2 type immunity and mediate the elimination of the worm $[24,25]$. Anti-Ascaris IgE is thought to play a role in the elimination of the helminth to protect the host against infection. Since allergic manifestations have been described in anisakiasis [28], anti-Ascaris IgE may cause allergic reactions likewise [29-31]. The cross-reactivity between Ascaris and mite tropomyosin might be partially responsible for this mechanism, although it is entirely unclear how anti-Ascaris IgE works in the mechanism underlying the development of wheezing [34-37]. Inhalation of the Der $p$ antigen present at high levels in the en- vironment might result in its combination with anti-Ascaris IgE on the mast cell surface in the airways, causing mast cell degranulation and wheezing.

The hierarchical cluster analysis of the wheezing children in the present study found that $11 \%$ of the wheezing cases were due to anti-Ascaris IgE (Table 5). This group is assumed to have a predisposition to atopy that results in the production of high titers of anti-Ascaris IgE when infected with Ascaris. In a 2001 study, 26\% of wheezing was associated with anti-Ascaris IgE [22]. The wheezing children in both the present and previous studies had elevated total and anti-Ascaris IgE levels and slightly higher anti-Der $p$ and anti-cockroach IgE titers than those of the never-wheezing children. Cluster 3 may resemble a multisensitized atopic wheezing cluster, as identified in other studies [38]. However, cluster 3 does not simply indicate an atopic population, since anti-Der $p$ and anticockroach IgEs did not increase or decrease the risk of wheezing in the participants of the present study.

Cluster 2 was characterized by a high prevalence of pneumonia. This group may correspond to cluster 3 in the 2001 study and to a group of asthma patients who presented with wheezing, before the age of 7 years, which later resolved as proposed by Stein et al. [39]. Cluster 1 was the largest cluster in which we could not find any specific characteristics using the classification method based on total and specific levels of IgE, parental asthma, Ascaris infection prevalence, vaccination history, and pneumonia history. This group might correspond to the nonatopic wheezers presented by Stein et al. [39]. Specific risk factors which characterize this group might include some other precipitating factors such as air pollution, indoor pollution, or scabies, infection by Sarcoptes. Ascaris migrates through the lungs during maturation, and eosinophilic lung disease develops [40, 41]. Type 2 innate lymphoid cells, in addition to Th2 immunity, due to these factors might cause wheezing.

The present study had several strengths. First, the ORs of this study were adjusted for numerous covariates, such as sex, pneumonia history, parental asthma, helminth infections, Hib combination vaccination, antibiotic use during infancy, and total and specific IgEs, which seemed to affect the results of the analysis [33]. Second, the participants were randomly selected from the general population, even though the study was conducted in a low- to middle-income country. Finally, the response rate exceeds $80 \%$.

There are also some limitations. First, we used a questionnaire to diagnose asthma rather than AHR. This was because AHR testing is a difficult procedure for children 
aged 5 years. Next, we speculated that there must have been differences in the results of the effects of some predictors, such as the history of pneumonia and anti-Der $p$ IgE. Although a history of pneumonia at the age of 2 years or above increased the risk of wheezing in the overall population of the first cross-sectional survey [20,21], this was not confirmed in this case-control study. This was caused by the smaller final sample size than our initial expectation. The unforeseen drop in the prevalence of wheezing may be due to the implementation of the national deworming program and the start of Hib combination vaccination $[21,41]$.

\section{Conclusions}

Anti-Ascaris IgE was found to increase the risk of wheezing among children from the general population in rural Bangladesh despite the decreased prevalence of $A s$ caris infection. This indicates the robustness of the risk posed by anti-Ascaris IgE irrespective of the prevalence of Ascaris infection. The ORs for wheezing were increased when only children with more specific symptoms of asthma were included in the analysis, and $11 \%$ of the cases were associated with anti-Ascaris IgE, thus providing further support for our conclusions. These imply that Ascaris causes a serious public health concern in low- and middle-income countries, since it may participate in childhood wheezing through both acquired and innate immunity and infects 447 million people in impoverished areas worldwide. The role of anti-Ascaris IgE, as well as the role of innate immunity, in the underlying mechanism of wheezing development requires further investigation.

followed the ethical principles of the Declaration of Helsinki. Written informed consent was obtained from all the participants' legal guardians, and their anonymity was preserved using the methods approved by each ethics committee.

\section{Conflict of Interest Statement}

All the authors confirm that there are no conflicts of interest to disclose.

\section{Funding Sources}

This work was funded by a Grant-in-Aid for Scientific Research 26257507 (Basic Research [A]) in 2014-2016 from the Ministry of Education, Culture, Sports, Science and Technology, Japan. icddr,b is grateful to the Governments of Bangladesh, Canada, Sweden, and the UK for providing core/unrestricted support.

\section{Author Contributions}

H.T., S.T., M.J., M.A.K., and T.I. made substantial contributions to the study planning. All authors contributed to the study design and protocol writing. S.M.T.H., S.K.H., S.Y., S.M.A., M.J.A., and M.A.K. contributed substantially to data collection. H.T., S.T., S.M.T.H., M.J., M.A.K., and T.I. contributed substantially to data analysis and interpretation of the results. All authors were involved in drafting and revising the manuscript. All authors read and approved the final submitted version of the manuscript.

\section{Data Availability Statement}

All data generated or analyzed during this study are included in the online supplementary files of this article. Further enquiries can be directed to the corresponding author.

\section{Acknowledgments}

The authors thank the children who participated in the studies and offered precious blood and stool samples and their guardians who accompanied them. They also thank the field research staff for their rigorous data collection. They also thank Dr. Akira Shibanuma for the statistical analysis.

\section{Statement of Ethics}

The study protocol PR-15054 was approved by the Ethical Review Committee of icddr,b. The Ethics Committee of Tokyo Kasei University approved the study protocol, Sayama H27-09, and protocol 11018 was approved by the Ethics Committee of the University of Tokyo. This study involved human subjects, and therefore

\section{References}

Wheezing and Anti-Ascaris IgE with Decreased Ascaris Infection Prevalence
1 Kusel MM, de Klerk NH, Kebadze T, Vohma V, Holt PG, Johnston SL, et al. Early-life respiratory viral infections, atopic sensitization, and risk of subsequent development of persistent asthma. J Allergy Clin Immunol. 2007 May;119(5):1105-10.

2 Palmer LJ, Celedón JC, Weiss ST, Wang B, Fang Z, Xu X. Ascaris lumbricoides infection is associated with increased risk of childhood asthma and atopy in rural China. Am J Respir Crit Care Med. 2002 Jun 1;165(11):1489-93.

3 Leonardi-Bee J, Pritchard D, Britton J. Asthma and current intestinal parasite infection: systematic review and meta-analysis. Am J Respir Crit Care Med. 2006 Sep 1;174(5):514-23.

4 Ardura-Garcia C, Garner P, Cooper PJ. Is childhood wheeze and asthma in Latin America associated with poor hygiene and infection? A systematic review. BMJ Open Respir Res. 2018 Feb 22;5(1):e000249. 
5 Mohammadzadeh I, Rostami A, Darvish S, Mehravar S, Pournasrollah M, Javanian M, et al. Exposure to Ascaris lumbricoides infection and risk of childhood asthma in north of Iran. Infection. 2019 Dec;47(6):991-9.

6 Zakzuk J, Casadiego S, Mercado A, AlvisGuzman N, Caraballo L. Ascaris lumbricoides infection induces both, reduction and increase of asthma symptoms in a rural community. Acta Trop. 2018 Nov; 187:1-4.

7 Jõgi NO, Svanes C, Siiak SP, Logan E, Holloway JW, Igland J, et al. Zoonotic helminth exposure and risk of allergic diseases: a study of two generations in Norway. Clin Exp Allergy. 2018 Jan;48(1):66-77.

8 Scrivener S, Yemaneberhan H, Zebenigus M, Tilahun D, Girma S, Ali S, et al. Independent effects of intestinal parasite infection and domestic allergen exposure on risk of wheeze in Ethiopia: a nested case-control study. Lancet. 2001 Nov 3;358(9292):1493-9.

9 Cooper PJ, Chis Ster I, Chico ME, Vaca M, Oviedo Y, Maldonado A, et al. Impact of early life geohelminths on wheeze, asthma and atopy in Ecuadorian children at 8 years. Allergy. 2021 Sep;76(9):2765-75.

10 Medeiros M Jr, Figueiredo JP, Almeida MC, Matos MA, Araújo MI, Cruz AA, et al. Schistosoma mansoni infection is associated with a reduced course of asthma. J Allergy Clin Immunol. 2003 May;111(5):947-51.

11 Nyan OA, Walraven GE, Banya WA, Milligan P, Van Der Sande M, Ceesay SM, et al. Atopy, intestinal helminth infection and total serum IgE in rural and urban adult Gambian communities. Clin Exp Allergy. 2001 Nov;31(11): $1672-8$.

12 Worldwide variation in prevalence of symptoms of asthma, allergic rhinoconjunctivitis, and atopic eczema: ISAAC. The International Study of Asthma and Allergies in Childhood (ISAAC) Steering Committee. Lancet. 1998 Apr 25;351(9111):1225-32.

13 Sears MR. Descriptive epidemiology of asthma. Lancet. 1997 Oct;350 Suppl 2:SII1-4.

14 Stein MM, Hrusch CL, Gozdz J, Igartua C, Pivniouk V, Murray SE, et al. Innate immunity and asthma risk in Amish and Hutterite farm children. N Engl J Med. 2016 Aug 4; 375(5):411-21.

15 Addo Yobo EO, Custovic A, Taggart SC, Asafo-Agyei AP, Woodcock A. Exercise induced bronchospasm in Ghana: differences in prevalence between urban and rural schoolchildren. Thorax. 1997 Feb;52(2):161-5.

16 Pearce N, Aït-Khaled N, Beasley R, Mallol J, Keil U, Mitchell E, et al. Worldwide trends in the prevalence of asthma symptoms: phase III of the International Study of Asthma and Allergies in Childhood (ISAAC). Thorax. 2007 Sep;62(9):758-66.

17 van den Biggelaar AH, van Ree R, Rodrigues LC, Lell B, Deelder AM, Kremsner PG, et al. Decreased atopy in children infected with Schistosoma haematobium: a role for parasiteinduced interleukin-10. Lancet. 2000 Nov 18; 356(9243):1723-7.
18 Wilson MS, Taylor MD, Balic A, Finney CA, Lamb JR, Maizels RM. Suppression of allergic airway inflammation by helminth-induced regulatory T cells. J Exp Med. 2005 Nov 7; 202(9):1199-212.

19 Calvert J, Burney P. Ascaris, atopy, and exercise-induced bronchoconstriction in rural and urban South African children. J Allergy Clin Immunol. 2010 Jan;125(1):100-5.

20 Takeuchi H, Zaman K, Takahashi J, Yunus M, Chowdhury HR, Arifeen SE, et al. High titre of anti-Ascaris immunoglobulin $\mathrm{E}$ associated with bronchial asthma symptoms in 5-yearold rural Bangladeshi children. Clin Exp Allergy. $2008 \mathrm{Feb}$;38(2):276-82.

21 Takeuchi H, Khan MA, Ahmad SM, Hasan SMT, Md Alam J, Takanashi S, et al. Concurrent decreases in the prevalence of wheezing and Ascaris infection among 5-year-old children in rural Bangladesh and their regulatory $\mathrm{T}$ cell immunity after the implementation of a national deworming program. Immun Inflamm Dis. 2019 Sep;7(3):160-9.

22 Takeuchi H, Khan AF, Yunus M, Hasan MI, Hawlader MDH, Takanashi S, et al. Anti-Ascaris immunoglobulin $\mathrm{E}$ associated with bronchial hyper-reactivity in 9-year-old rural Bangladeshi children. Allergol Int. 2016 Apr; 65(2):141-6.

23 Takeuchi H, Khan MA, Zaman K, Takanashi S, Hasan SMT, Yunus M, et al. Classification of wheezing children in Rural Bangladesh by intensity of Ascaris infection, total and specific IgE levels, history of pneumonia, and other risk factors. J Immunol Res. 2019;2019:4236825.

24 King CL, Xianli J, Malhotra I, Liu S, Mahmoud AA, Oettgen HC. Mice with a targeted deletion of the IgE gene have increased worm burdens and reduced granulomatous inflammation following primary infection with Schistosoma mansoni. J Immunol. 1997 Jan 1; 158(1):294-300.

25 Gurish MF, Bryce PJ, Tao H, Kisselgof AB, Thornton EM, Miller HR, et al. IgE enhances parasite clearance and regulates mast cell responses in mice infected with Trichinella spiralis. J Immunol. 2004 Jan 15;172(2):1139-45.

26 Matsumoto M, Sasaki Y, Yasuda K, Takai T, Muramatsu M, Yoshimoto T, et al. IgG and IgE collaboratively accelerate expulsion of Strongyloides venezuelensis in a primary infection. Infect Immun. 2013 Jul;81(7):2518-27.

27 Liu Q, Kreider T, Bowdridge S, Liu Z, Song Y, Gaydo AG, et al. B cells have distinct roles in host protection against different nematode parasites. J Immunol. 2010 May 1;184(9):5213-23.

28 Alonso A, Daschner A, Moreno-Ancillo A. Anaphylaxis with Anisakis simplex in the gastric mucosa. N Engl J Med. 1997 Jul 31;337(5): $350-1$.

29 Alcântara-Neves NM, Badaró SJ, dos Santos MC, Pontes-de-Carvalho L, Barreto ML. The presence of serum anti-Ascaris lumbricoides IgE antibodies and of Trichuris trichiura infection are risk factors for wheezing and/or atopy in preschool-aged Brazilian children. Respir Res. 2010;2311(1):114.
30 Moncayo AL, Vaca M, Oviedo G, Workman LJ, Chico ME, Platts-Mills TA, et al. Effects of geohelminth infection and age on the associations between allergen-specific IgE, skin test reactivity and wheeze: a case-control study. Clin Exp Allergy. 2013 Aug 23;11(1):60-72.

31 Hawlader MD, Ma E, Noguchi E, Itoh M, Arifeen SE, Persson LÅ, et al. Ascaris lumbricoids infection as a risk factor for asthma and atopy in rural Bangladeshi children. Trop Med Health. 2014 Jun;42(2):77-85.

32 Health and demographic surveillance systemMATLAB 51. Registration of health and demographic events 2016. Scientific report. Dhaka: icddr,b; 2018. Report No.: 138. Available from: http://dspace.icddr,b.org/jspui/ handle/123456789/9061 Accessed 2021 Jul 23.

33 Takeuchi H, Hasan SMT, Zaman K, Takanashi S, Hore SK, Yeasmin S, et al. Impact of Haemophilus influenzae type $\mathrm{b}$ combination vaccination on asthma symptoms and pneumonia in 5-year-old children in rural Bangladesh: a longitudinal study and comparison with a previous cross-sectional study. Respir Res. 2021 Feb 3;22(1):35.

34 Santos AB, Rocha GM, Oliver C, Ferriani VP, Lima RC, Palma MS, et al. Cross-reactive IgE antibody responses to tropomyosins from $A s$ caris lumbricoides and cockroach. J Allergy Clin Immunol. 2008 Apr;121(4):1040-6.e1.

35 Acevedo N, Sánchez J, Erler A, Mercado D, Briza P, Kennedy M, et al. IgE cross-reactivity between Ascaris and domestic mite allergens: the role of tropomyosin and the nematode polyprotein ABA-1. Allergy. 2009 Nov; 64(11):1635-43.

36 Acevedo N, Erler A, Briza P, Puccio F, Ferreira F, Caraballo L. Allergenicity of Ascaris lumbricoides tropomyosin and IgE sensitization among asthmatic patients in a tropical environment. Int Arch Allergy Immunol. 2011;154(3):195-206.

37 Ahumada V, García E, Dennis R, Rojas MX, Rondón MA, Pérez A, et al. IgE responses to Ascaris and mite tropomyosins are risk factors for asthma. Clin Exp Allergy. $2015 \mathrm{Jul}$; 45(7):1189-200.

38 Savenije OE, Granell R, Caudri D, Koppelman GH, Smit HA, Wijga A, et al. Comparison of childhood wheezing phenotypes in 2 birth cohorts: ALSPAC and PIAMA. J Allergy Clin Immunol. 2011 Jun;127(6):1505-12.e14.

39 Stein RT, Holberg CJ, Morgan WJ, Wright $\mathrm{AL}$, Lombardi E, Taussig L, et al. Peak flow variability, methacholine responsiveness and atopy as markers for detecting different wheezing phenotypes in childhood. Thorax. 1997 Jun;127(6):946-52.

40 Loffler W. Zur differential-diagnose der lungeninfiltrierungen II uber fluchtige succedaninfiltrate (mit eosinophilie). Beitr Klin Tuberk. 1932;79:368. German.

41 Weatherhead JE, Porter P, Coffey A, Haydel $D$, Versteeg L, Zhan B, et al. Ascaris larval infection and lung invasion directly induce severe allergic airway disease in mice. Infect Immun. 2018 Nov 20;86(12):e00533-18. 